American Journal of Environmental Sciences 4 (3): 238-244, 2008

ISSN 1553-345X

(C) 2008 Science Publications

\title{
Physical Characterizations of Sands and Their Influence in Fall Velocity
}

\author{
Ruiz-Martinez Gabriel, Mendoza-Baldwin Edgar, Silva-Casarín Rodolfo \\ Coordinación de Hidráulica, Instituto de Ingeniería, Universidad Nacional Autónoma de Mexico
}

\begin{abstract}
Cancun beach is one of the most important tourist resorts on the Mexican coast, and is of prime importance to the local and national economies. As a result of the intense use of the beach and the unavailability of sand reserves, the extreme weather events that occur in the region (hurricanes) have permanently damaged the beach. Over the last two decades several strong hurricanes severely weakened the system, but hurricane Wilma, October 2005, caused devastating erosion to the beach. After Wilma, an emergency nourishment project was implemented pumping a volume of 2.7 million $\mathrm{m}^{3}$ of sand onto the beach. Clearly, the sand used for the nourishment has a different shape factor, diameter distribution and density property compared to the native sand. The main goal of this paper is to characterize and compare the fall velocities of sand samples taken in and around Cancun. The settling velocities obtained for several samples were compared with the empirical formulations proposed by various authors. The influence of several parameters measured in the laboratory is discussed and a new formulation is presented.
\end{abstract}

Keywords: Settling velocity, Cancun sands, sediment physical properties

\section{INTRODUCTION}

Cancun is a $17 \mathrm{~km}$ long, barrier island located in the North East of the Yucatan peninsula, in the state of Quintana Roo, on the Mexican Caribbean (Fig. 1). The development of this resort over the last 40 years has broken several natural equilibriums. As a result, the effects of a series of strong hurricanes produced chronic erosion problems between Punta Cancun and Punta Nizuc. Following the devastation of hurricane Wilma (2005), a beach nourishment program was begun in 2006 with 2.7 million cubic meters of sand used to nourish the beach system. The material employed to fill the beach has different mechanical properties compared to the original sand and that found in the surrounding area. It is now very important to estimate the potential behavior of this new beach.

The settling velocity of beach material is a very important parameter when analyzing the stability of a beach; the processes of advance or retreat of a coastline under a given wave climate are obviously influenced by it. Traditional theoretical formulae for estimating fall velocity considered sand grains as spherical ${ }^{[1]}$. This has since been demonstrated to be a false assumption which over-estimates its relation to settling velocity. Overcoming the spherical assumption, many other formulae have been developed, i.e. those by $\mathrm{Graf}^{[2]}$,
Hallermeier $^{[3]}$, Dietrich ${ }^{[4]}$, van Rijn ${ }^{[5]}$, Soulsby ${ }^{[6]}$ and Ahrens ${ }^{[7]}$; all of which were derived empirically but validated with the same data set used to get the equations. The common path of the aforementioned formulae depends on sediment diameter and shape factor (some of them with the usage of the nominal diameter). But a simple look at the distribution of the physical properties of the sand along the beach and across the beach profile, in combination with the wave energy, indicates that the fall velocity may also be governed by other parameters.

This paper presents the results of field and laboratory work conducted to investigate the influence of physical properties of sand samples taken from Quintana Roo, Mexico and their relation to fall velocity. The analysis of all the data compiled gives an idea of the parameters involved in the settling process and the physical characterization of the sand studied.

\section{FIELD WORK}

The sand transport along and across a beach is difficult to understand because of the variety of processes involved and the ways in which these occur. Nevertheless, once the material is deposited at the bottom, the distribution of the sand properties and grain sizes can be used to get an idea of the equilibrium state

Corresponding Author: Ruiz-Maritnez Gabriel, Circuito Escolar s/n, Edificio 5, Cub. 414-C, Instituto de Ingeniería, Ciudad Universitaria, 04510, Coyoacán, México, DF, México. Tel: +52(55)56233600 ext. 8633, Fax: $+52(55) 56162798$ 
of the beach. For example, in a stable beach, the bigger particles should be found above the mean sea level, while in the surf zone more rounded grains are expected to appear. In turn, an eroding beach may have particles with a higher flotation index close to the swash zone.

In order to get a comprehensive view of the grain size and physical properties distributed across various beach profiles and along a $40 \mathrm{~km}$ stretch of coast, several sand samples were taken in Quintana Roo, Mexico from Punta Sam to Puerto Morelos (see Fig. 1).

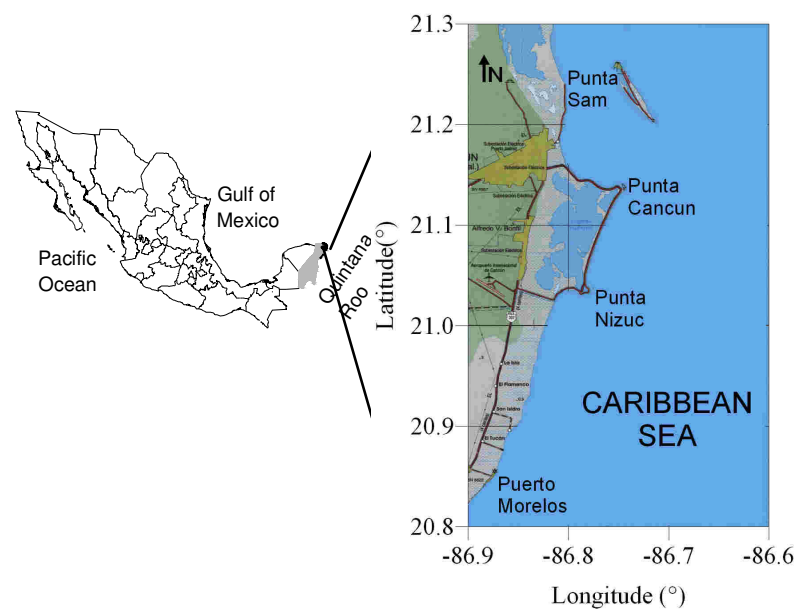

Fig 1: Location of the littoral cell of interest

In planning the sampling logistics and procedures, the main idea was that at least three points across the beach profile should be sampled 1) at the beach berm, 2) at the swash zone and 3) close to the breaking zone (approx. $1 \mathrm{~m}$ below the mean water level). Each of these samples afford specific information, that is, the berm shows the material that has not been moved by the waves or tides and is expected to have been settled for a longer time than in the other zones. The sample from the swash zone gives information related to the mixture of the sand and the water, this material has been carried by the breaking waves during its energy loss process. Finally the breaking zone supplies data on the material that has stayed at the bottom after the steeping and breaking of the waves. All the samples were taken at the sand surface and the approximate weight of each sample was $2.0 \mathrm{~kg}$.

The sampling sites along the coast line were selected, assuring that at least one sample was taken from every littoral cell between Punta Sam and Punta Nizuc. The three samples at Puerto Morelos were taken as representative of the littoral cell there. Each site was identified with the UTM coordinates given by a manual DGPS so that the same places can be sampled again in the future. In Table 1 the ID codes and coordinates of the 22 sample points are listed.

The ID number is completed with a letter $\mathrm{B}, \mathrm{L}$ or $\mathrm{S}$ which stands for berm, swash and breaking zone, respectively.

Figures 2 to 4 show the position of each sampling site between Punta Sam and Punta Cancun (A to G), between Punta Cancun and Punta Nizuc (Boca Sur and P1 to P10) and at Puerto Morelos (PM1, PM2 and PM3), respectively.

Table 1: Sampling points list and UTM coordinates

\begin{tabular}{|c|c|c|c|c|}
\hline \multirow{2}{*}{\multicolumn{2}{|c|}{ Number }} & \multirow[b]{2}{*}{ UTM } & \multirow{2}{*}{$\begin{array}{c}x \\
\text { UTM } \\
\end{array}$} & \multirow[t]{2}{*}{$\mathrm{y}$} \\
\hline & & & & \\
\hline 1 & $\mathrm{Bo}$ & $21,259.9992$ & $2,326,122.1175$ & \\
\hline 2 & & & $513,801.1374$ & $2,307,548.0139$ \\
\hline 3 & & & $513,943.9119$ & $2,307,851.8631$ \\
\hline 4 & & & $513,664.9397$ & $2,307,322.5620$ \\
\hline 5 & 1 & $526,453.7885$ & $2,336,940.7871$ & \\
\hline 6 & 2 & $526,150.4047$ & $2,336,595.8547$ & \\
\hline 7 & 3 & $526,017.6126$ & $2,336,409.6325$ & \\
\hline 8 & 4 & $525,154.7245$ & $2,334,853.4970$ & \\
\hline 9 & $4 \mathrm{~A}$ & $524,605.0000$ & $2,333,629.0000$ & \\
\hline 10 & 5 & $524,218.9638$ & $2,332,622.0587$ & \\
\hline 11 & 6 & $523,456.9477$ & $2,330,419.6613$ & \\
\hline 12 & 7 & $522,951.5196$ & $2,328,850.9625$ & \\
\hline 13 & 8 & $522,652.5128$ & $2,327,388.3438$ & \\
\hline 14 & 9 & $522,664.9844$ & $2,326,847.3934$ & \\
\hline 15 & 10 & $522,860.8821$ & $2,326,243.7693$ & \\
\hline 16 & A & $525,843.9993$ & $2,337,619.1441$ & \\
\hline 17 & B & $526,088.0000$ & $2,337,574.0283$ & \\
\hline 18 & $\mathrm{C}$ & $523,442.0098$ & $2,338,090.0004$ & \\
\hline 19 & $\mathrm{D}$ & $522,114.0006$ & $2,338,094.0011$ & \\
\hline 20 & $\mathrm{E}$ & $522,285.0002$ & $2,338,171.9409$ & \\
\hline 21 & $\mathrm{~F}$ & $520,133.9994$ & $2,341,716.0157$ & \\
\hline 22 & $\mathrm{G}$ & $520,531.1592$ & $2,348,845.8938$ & \\
\hline
\end{tabular}

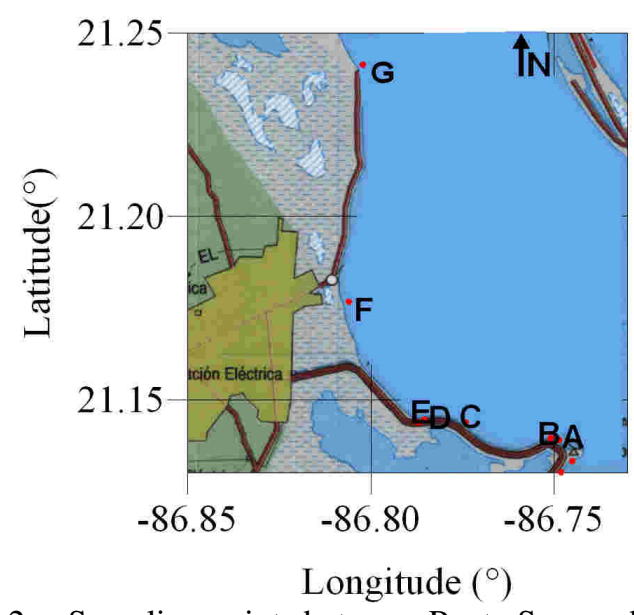

Fig. 2: Sampling points between Punta Sam and Punta Cancun 


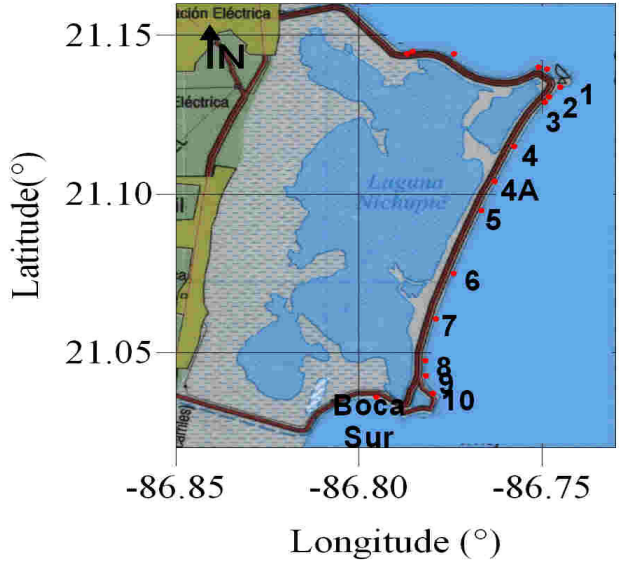

Fig. 3: Sampling points between Punta Cancun and Punta Nizuc

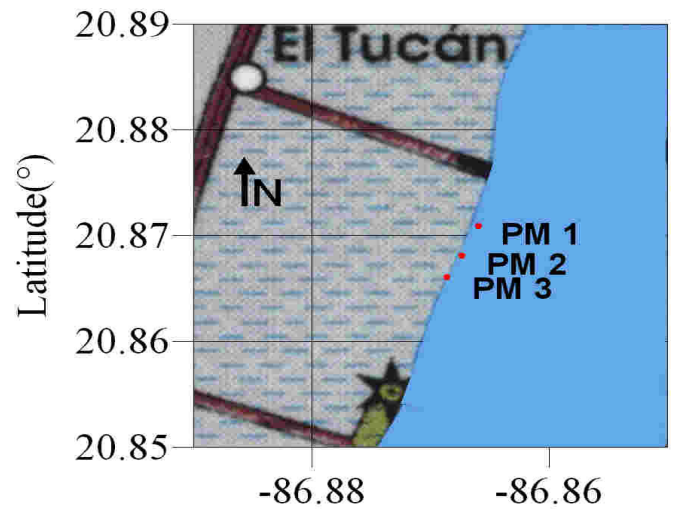

Longitude $\left({ }^{\circ}\right)$

Fig. 4: Sampling points at Puerto Morelos

A total of 60 sand samples were characterized in the Coastal and Port Laboratory of the Institute of Engineering at the National Autonomous University of Mexico.

\section{LABORATORY WORK}

Most of the sand samples arrived at the laboratory damp or wet. To dry out the samples two processes were used: 1) a pre-drying, which consisted of heating the samples using very intense light for 12 to 24 hours and 2) full drying in an oven at $110^{\circ} \mathrm{C}$ for 10 to 12 hours. Once the samples were completely dried, the net weight could be measured. The samples were then analysed, characterizing grain size distribution, density, Corey shape factor and settling velocity.

The grain distribution characterization was carried out using a series of 15 sieves $(16,4.00,2.36,2.00$, $1.40,1.00,0.71,0.50,0.355,0.250,0.180,0.125,0.090$, 0.063 and $0.053 \mathrm{~mm}$ ) which were shaken with an electric Ro-Top machine for 7.5 minutes. The material retained in each sieve was weighed with an electronic scale. Examples of the some of the curves obtained can be seen in Figs. 5 and 6.

All the samples contained at least $90 \%$ sand. In most cases the additional material was very fine, although in some samples big particles of organic material were also present.

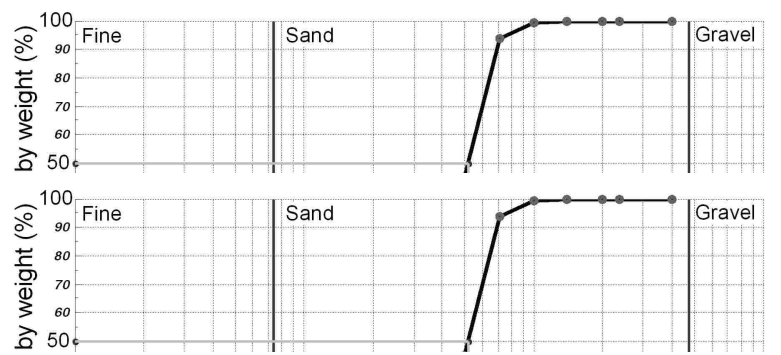

Fig. 5: Grain distribution curve for sample PL 1

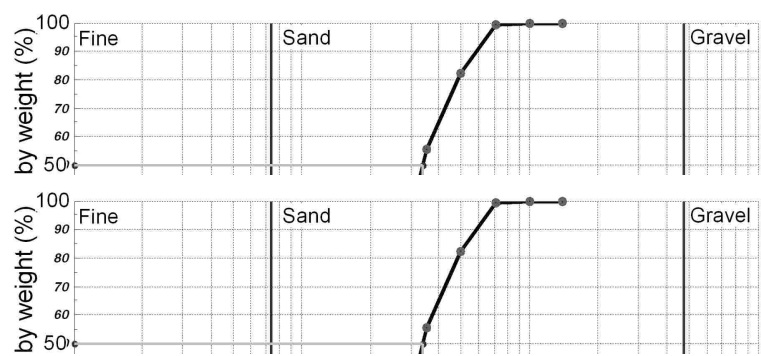

Fig.6: Grain distribution curve for sample PB 1

To find the density of each sand sample the sand retained by sieve No.5 $(4 \mathrm{~mm})$ was used and divided into two samples, $S_{1}=0.04 \mathrm{~kg}$ and $S_{2}=0.02 \mathrm{~kg}$. Two empty 100 and $50 \mathrm{ml}$ volumetric flasks were weighed, $W_{s 1}$ and $W_{s 2}$, respectively, while $W_{f w 1}$ and $W_{f w 2}$ correspond to the weights of the flasks when full of distilled water. Sands $S_{1}$ and $S_{2}$ were poured into the flasks and the excess water removed. Both flasks were then put into boiling water for 15 to 20 minutes, and then taken out. Once the flasks were at room temperature, the volume of the mixture was modified with distilled water to 100 or $50 \mathrm{ml}$ and the flasks were again weighed, $W_{f s w l}$ and $W_{f s w 2}$. The relative density of the sand was thus estimated:

$S_{s}=W_{s} /\left(W_{s}+W_{f w}-W_{f s w}\right)$

The average of $S_{s l}$ and $S_{s 2}$ was taken as the density of each sample. Table 2 shows some of the densities obtained. $(\mathrm{PL}=$ breaking zone; $\mathrm{PS}=$ swash zone; $\mathrm{PB}=$ beach berm)

The shape factor was measured using digital photographs of a small amount of sand with a grain size close to $\mathrm{D}_{50}$ (the material retained by the first sieve was finer than the $\left.\mathrm{D}_{50}\right)$. The photographs were analyzed one by one and the dimensions length, $a$, width, $b$ and thickness, $c$, of the grains obtained with a MATLAB 
process. The Corey shape factor, CSF, was then computed as:

$C S F=c /(a b)^{1 / 2}$

Table 2: Densities of selected sand samples

\begin{tabular}{lll}
\hline ID & \multicolumn{1}{c}{$S_{s}$} & \\
\hline PL PM1 & & 2.668 \\
PS PM2 & 2.759 & 2.721 \\
PB 1 & & 2.658 \\
PB 4A & 2.817 & \\
PL 5 & 2.649 & \\
PS 7 & 2.768 & \\
PL 9 & & \\
PB 10 & 2.540 \\
PS C & 2.749 & \\
PB F & 2.749 & \\
PR F & 2.210 & \\
PL F & 2.532 & \\
PS F & & \\
\hline
\end{tabular}

Figure 7 shows an example of photographs taken with a micro lens, and Table 3 lists some Corey factors.
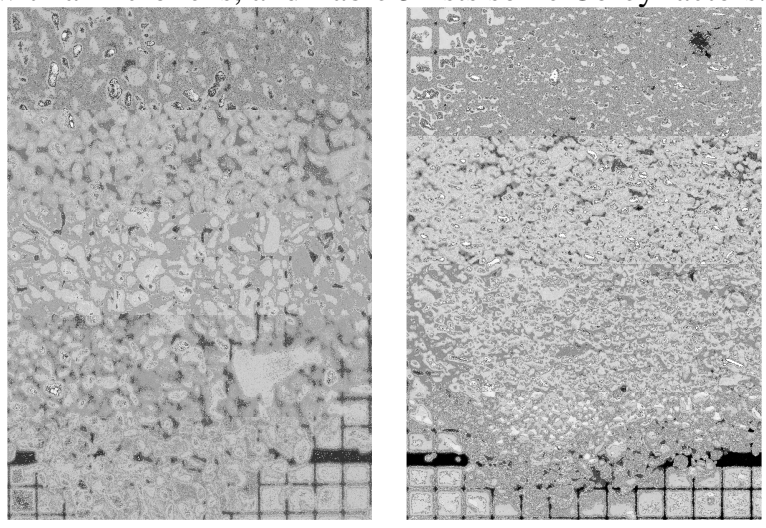

Fig.7: Examples of sand grain photographs. Sample PL 5 (left) and sample PR PM2 (right). Grid mesh $=1 \mathrm{~mm}$.

Table 3: $\quad$ CSF of selected sand samples

\begin{tabular}{lll}
\hline ID & \multicolumn{1}{c}{ CSF } & \\
\hline PL PM1 & & 0.6815 \\
PS PM2 & & 0.7545 \\
PB 1 & 0.7452 & \\
PB 4A & & 0.7600 \\
PL 5 & 0.6158 & \\
PS 7 & 0.6974 & \\
PL 9 & 0.7869 & 0.6270 \\
PB 10 & & \\
PS C & 0.6847 & \\
PB F & 0.7344 & \\
PR F & 0.6083 & \\
PL F & 0.8118 & \\
PS F & 0.6558 & \\
\hline
\end{tabular}

The settling velocity was measured manually using a static water recipient. Sand grains with sizes close to D50 were left on the water surface and then touched lightly, just enough to break the surface tension and allow them to drop down and the time was recorder in milliseconds and the distance in millimeters. Some results are shown in Table 4.

\section{DISCUSSION}

In order to characterize settling velocities a comparison was made between the measured settling velocities and the values given by other authors. The formulations by Rubey ${ }^{[8]}$, Hallermeier ${ }^{[4]}$, van Rijn ${ }^{[5]}$, Julien $^{[9]}$, Cheng ${ }^{[10]}$, Soulsby ${ }^{[6]}$, Ahrens ${ }^{[7]}$, Chang \& Liou $^{[11]}$ and Jimenez \& Madsen ${ }^{[12]}$ were used. Figure 8 shows the match of the measured data with the nine empirical formulae.

At first sight the values given by van $\mathrm{Rijn}^{[5]}$, Julien $^{[9]}$ and Cheng ${ }^{[10]}$ are very close to the measured velocities. In order to achieve a quantitative dimension, the average relative error of each formula was calculated. These errors are presented in Table 5.

It is clear from Table 5 that the formula that best fits with the measured data is that of Julien ${ }^{[9]}$, in which the main parameters considers are material density and grain size $\left(D_{50}\right)$. Their relation with the measured fall velocity is presented in Fig. 9. In this figure, it is very clear that for the range of settling velocities found in the littoral cell in study, the influence of density is not relevant. Furthermore grains with almost the same density have very different fall velocities and no tendency can be seen in the values. However, this does not mean that if a wider range of relative densities were compared some influence could not be detected. In this particular case, all the material has the same geological origin, thus the densities are very similar, but not so the fall velocities.

It is important to note that the material being studied is fine to medium sand with almost no cohesive material. The very small grain sizes found in these samples led to an analysis of the shape factor and the fall velocity of the grains and are shown in Fig. 10.

Since the formula of Julien ${ }^{[9]}$ gives the best fit and density and shape are not relevant, only the $\mathrm{D}_{50}$ would seem to govern the settling velocity for the samples taken. The relation between $\mathrm{D}_{50}$ and fall velocity is shown in Fig. 11.

As expected, the $\mathrm{D}_{50}$ shows a clear tendency. Now it is easy to get a relation of the settling velocity as a function of the grain size considering that other parameters showed little relevance in the values of the phenomenon. Equation (3) is the best fit curve for the values measured at the laboratory.

$\mathrm{Wf}=a\left(b-\exp \left(-c \mathrm{D}_{50}\right)\right)$ 
Am. J. Environ. Sci., 4 (3): 238-244, 2008

Table 4: Measured Wf of selected sand samples
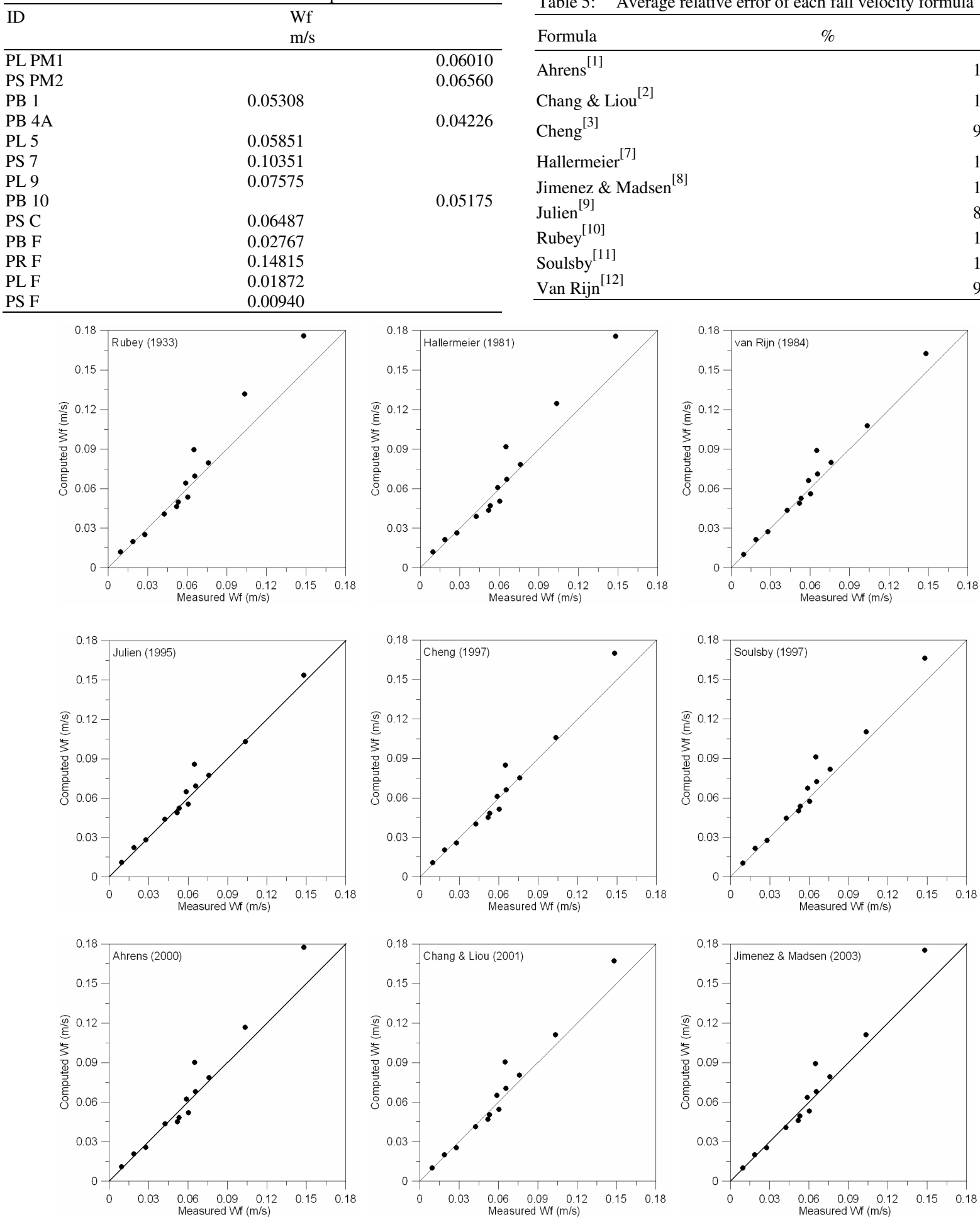

Fig. 8: Comparison of measured and theoretical (computed) settling velocities 


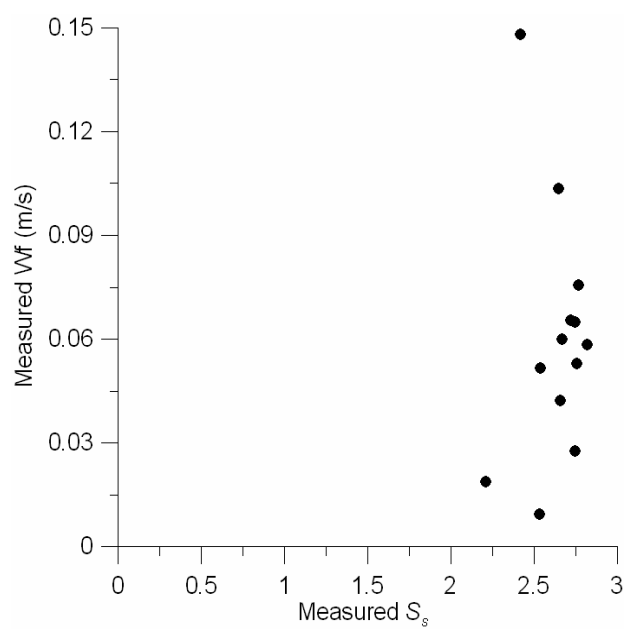

Fig. 9: Measured relative density versus fall velocity

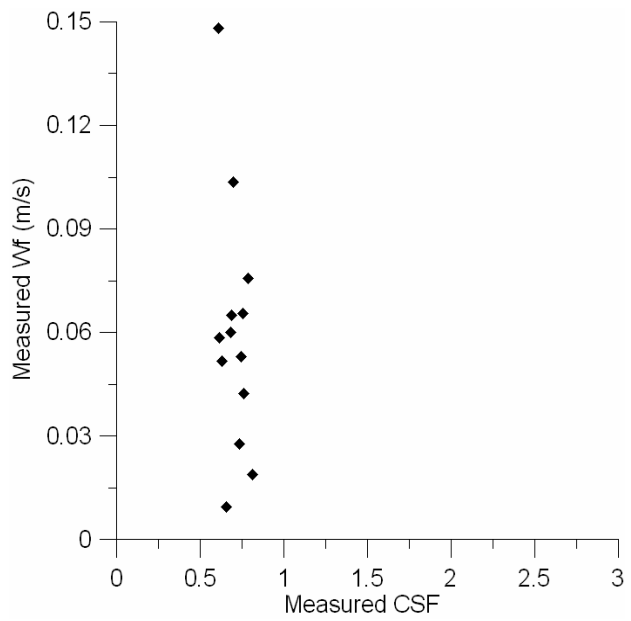

Fig.10: Measured Corey Shape Factor versus fall velocity

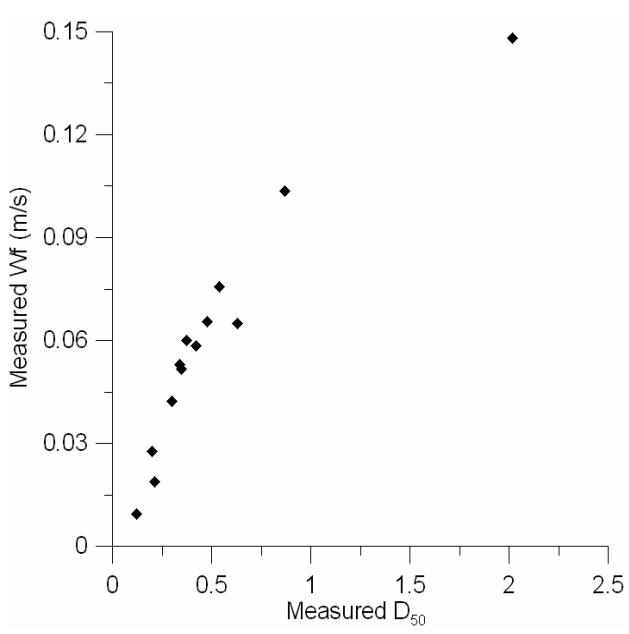

Fig.11: Measured $D_{50}$ in $m m$ versus fall velocity
Where $a=0.17 \mathrm{~m} / \mathrm{s}, \quad b=0.93$ and $c=1.23 \mathrm{~mm}^{-1}$ are empirical parameters applicable to the area of interest shown in Fig. 1. As a very simple validation exercise, the settling velocity of the 60 samples is calculated with equation (3) and compared to that computed with Julien $^{[9]}$ and shown in Fig. 12.

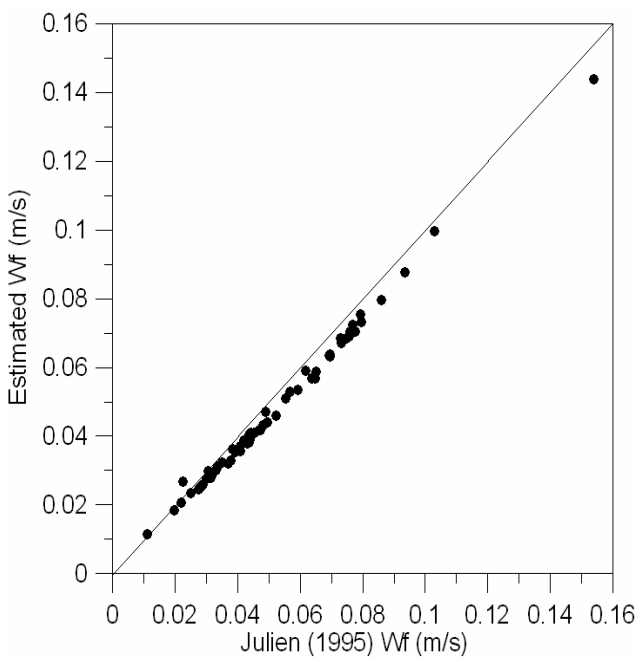

Fig.12: Wf estimated with ec (3) versus Julien (1995)

It can be seen that equation (3) slightly underestimates the velocities but the average relative error is only $8.69 \%$. The approximation given by equation (3) is a very simple method to get the settling velocity for the material within the littoral cell studied and useful for engineering applications.

\section{CONCLUSIONS}

The measurement of certain physical parameters of 60 sand samples, taken around Cancun, Quintana Roo, Mexico were analysed, measuring grain size distribution, relative density and Corey shape factor.

The relation between the properties measured and the settling velocity was investigated. For the material in the littoral cell studied, no relevant influence in velocity was found with density and shape but a very clear dependence on grain size was detected.

The fall velocity obtained from laboratory procedures was compared with a group of nine empirical formulations with that of Julien ${ }^{[9]}$ agreeing best.

A simple relation to obtain settling velocity as a function of $\mathrm{D}_{50}$ was presented. This equation was 
validated with the theoretical data calculated with Julien [9] giving acceptable results.

\section{ACKNOWLEDGMENTS}

The authors would like to thank our sponsors from the federal and local governments for making this project possible (Fondos Mixtos CONACYT-Quintana Roo under contract FOMIX-QROO-16924).

\section{REFERENCES}

1. Gibbs, R.J., Mathews, M.D. and Link, D.A. 1971. The relationship between sphere size and settling velocity. J. Sediment. Petrol., 44(1), 7-18.

2. Graf, W.H. 1971. Hydraulics of sediment transport. McGraw-Hill, New York.

3. Hallermeier, R.J. 1981. Terminal settling velocity of commonly occurring sand grains. Sedimentology, 28, 859-865.

4. Dietrich, W.E. 1982. Settling velocity of natural particles. Water Resour., Res., 18(6), 1615-1626.

5. Van Rijn, L.C. 1993. Principles of sediment transport in rivers, estuaries and coastal seas. Aqua Publications, Amsterdam, The Netherlands.
6. Soulsby, R.L. 1997. Dynamics of marine sands. Thomas Telford, London, UK.

7. Ahrens, J.P. 2000. A fall velocity equation. J. Waterw., Port, Coastal, Ocean Eng., 126(2), 99102.

8. Rubey, W.W. 1933. Settling velocities of gravel, sand and silt particles. Am. J. Sci., 25(148), 325338.

9. Julien Y.P. 1995. Erosion and sedimentation. Cambridge University Press, Cambridege, UK.

10. Cheng, N.S. 1997. Simplified settling velocity formula for sediment particle. J. Hydraul. Eng., 132(2), 149-152.

11. Chang H.K. and Liou, J.C. 2001. Discussion of a free-velocity equation, by John P. Ahrens. J. Waterw., Port, Coastal, Ocean Eng., 127(4), 250251.

12. Jimenez J.A. and Madsen O.S. 2003. "A simple formula to estimate settling velocity of natural sediments." J. Waterw., Port, Coastal, Ocean Eng., 129(2), 70-78. 